\title{
Assess, adapt and act: a paediatric surgery division's initial approach in a rapidly evolving pandemic
}

\author{
Anand Sanmugam ${ }^{1} \cdot$ Ganesh Vythilingam $^{1} \cdot$ Srihari Singaravel $^{1} \cdot$ Shireen Anne Nah ${ }^{1}$
}

Accepted: 17 June 2020 / Published online: 27 June 2020

(c) Springer-Verlag GmbH Germany, part of Springer Nature 2020

\begin{abstract}
Purpose The COVID-19 pandemic has placed an unprecedented test on the delivery and management of healthcare services globally. This study describes the adaptive measures taken and evolving roles of the members of the paediatric surgery division in a developing country during this period.

Methods We adopted multiple adaptive strategies including changes to stratification of surgeries, out-patient services by urgency and hospital alert status, policy writing involving multidisciplinary teams, and redeployment of manpower. Modifications were made to teaching activities and skills training to observe social distancing and mitigate reduced operative learning opportunities. Roles of academic staff were expanded to include non-surgical duties.

Results The planned strategies and changes to pre COVID-19 practices were successful in ensuring minimal disruption to the delivery of essential paediatric surgical services and training. Despite the lack of established guidelines and literature outlining strategies to address the impact of this pandemic on surgical services, most of the initial measures employed were consistent with that of other surgical centres.

Conclusion Changes to delivery of surgical services and surgical training warrant a holistic approach and a constant reevaluation of practices with emergence of new experiences and guidelines.
\end{abstract}

Keywords Paediatric $\cdot$ Pediatric $\cdot$ Surgery $\cdot$ COVID-19 $\cdot$ Pandemic $\cdot$ SARS-CoV-2

\section{Introduction}

The COVID-19 pandemic has placed an unprecedented test on the delivery and management of healthcare services globally. The challenges faced by surgical specialties include, but are not limited to the risk of exposure to non-COVID-19 patients, transmission to healthcare workers (HCWs), judicious use and allocation of valuable resources such as ventilators, personal protective equipment (PPE), and blood products. As a result of this, several modifications in practices had to be instituted by surgical services across the globe.

Being a key provider of paediatric surgical services and training in a developing country, several changes to aspects of patient care and approaches to surgical training were adopted. The members of the paediatric surgery division

Anand Sanmugam

Anandshan@hotmail.com

1 Division of Paediatric Surgery, Department of Surgery, Faculty of Medicine, University of Malaya, Kuala Lumpur, Malaysia of University of Malaya Medical Centre (UMMC) assumed additional responsibilities to provide assistance to both frontline HCWs and the management, in areas in need of support. This study describes the adaptive measures taken and evolving roles of the members of this paediatric surgery division upon the characterisation of COVID-19 as a pandemic.

\section{Methods}

Malaysia is a developing country in South East Asia. UMMC is a 1600 -bedded hospital providing tertiary medical and surgical care to patients of all ages in the capital city of Malaysia, Kuala Lumpur. The Division of Paediatric Surgery UMMC is one of the two university hospitals that provides a structured paediatric surgical training program in the country. It is also one of the three hospitals providing surgical services to the paediatric age group in a population area of 7.2 million people. 
The first COVID-19 case was reported in Malaysia on 25th January 2020. UMMC was designated as one of the COVID-hospitals in the country, which meant that patients with COVID-19 would be tested, treated and provided intensive care support if required. A Movement Control Order (MCO) was issued by the government of Malaysia on 18th March 2020, allowing only the operation of essential services, 1 week after the World Health Organisation (WHO) had characterized COVID-19 as a pandemic. Upon announcement of the MCO, hospitals were designated as either COVID-19 hospitals (managing only COVID-19 patients), hybrid COVID-19 hospitals (admitting and managing both COVID-19 and non-COVID-19 patients) or non-COVID-19 hospitals. Our hospital was designated as a hybrid COVID-19 hospital. The other two paediatric surgical centres in the city centre were not designated as COVID19 hospitals.

At this point in time, in the absence of peer-reviewed guidelines, we had to adapt quickly by formulating guidelines in the provision and delivery of healthcare services. A UMMC COVID-19 taskforce was then setup to draw up guidelines addressing aspects of patient care, administration systems, resource sourcing and allocation, teaching and training. The Division of Paediatric Surgery UMMC undertook the following measures in response to the evolving challenges posed by this pandemic. These set of guidelines were unique to our hospital.

\section{Adaptation of clinical services}

\section{Operative services}

On the days leading up to the MCO, UMMC was receiving an increasing number of patients under investigation (PUIs) and COVID-19 positive patients. This resulted in several challenges including reduced number of anaesthetists providing general anaesthesia services, limited availability of blood products, and reallocation of PPEs to the Emergency Department (ED) and Intensive Care Unit (ICU).

The Department of Surgery operating theatre committee was formed to draw up a framework for operative surgical services during this period based on the hospital alert status. The hospital alert status was divided into three phases depending on COVID-19 patient load and available resources. The three phases were phase I-semi urgent setting, phase II-urgent setting and phase III-disaster setting. Based on this framework, members of the division convened to identify an appropriate stratification of operative services (Tables 1 and 2).

Depending on the hospital alert status, for cases that could not be performed (e.g., Semi Emergency Category $\mathrm{A} / \mathrm{B}$ or emergencies in a phase III disaster alert status), a referral system was put in place and urgent transfers for these patients were arranged to the other two paediatric surgery centres in the city, which are within a $13 \mathrm{~km}$ radius.

\section{Paediatric surgery out-patient clinics}

Paediatric surgery outpatient clinic services were suspended to minimise patient traffic and risk of COVID-19 exposure. Selected members of the division were granted access to the electronic medical records of patients scheduled for outpatient clinic visits for the next 3-months. Documentation of the most recent clinic visits, histopathological examination results, and imaging results was reviewed. This was accompanied by phone calls to patients' parents to enquire regarding their current condition. Patients were either given an appointment at a later date or in situations where the patients had to be seen as scheduled, and appointments were staggered across the 5 working days to ensure no crowding and enable appropriate physical distancing.

\section{Patient management and policy writing involving multidisciplinary teams}

Decisions on patient care requiring input form more than one discipline were no longer carried out on a 'face-to-face' manner in a shared meeting room. Online platforms such as Google Meet, Zoom, and Microsoft Teams were utilised to ensure physical distancing. Repeated engagements with our counterparts in the Department of Paediatric Medicine were vital in ensuring that clear workflows were established for

Table 1 Surgical procedures allowed to proceed by hospital alert status across all surgical specialties

\begin{tabular}{llc}
\hline $\begin{array}{l}\text { Phase I } \\
\text { Semi-urgent setting }\end{array}$ & Phase II & Phase III \\
\hline $\begin{array}{l}\text { Patient survivorship compromised if surgery } \\
\text { not performed within } 3 \text { months }\end{array}$ & $\begin{array}{c}\text { Patient survivorship compromised if surgery } \\
\text { not performed within days }\end{array}$ & Patient survivorship compromised if surgery not \\
$\begin{array}{c}\text { (Surgical specialties can perform acute emer- } \\
\text { gency surgeries, emergency surgeries and all } \\
\text { semi-emergencies- incl. Category A and B)* }\end{array}$ & $\begin{array}{c}\text { limited to acute emergencies, emergencies } \\
\text { and category-A semi-emergenies)* }\end{array}$ & (Surgical specialties are limited to performing \\
\end{tabular}

*Definitions of acute emergencies, acute emergencies, semi-emergencies category A/B were decided by individual specialties and approved by the Council of Surgeons, UMMC 
Table 2 Stratification of paediatric surgery cases by urgency in compliance to hospital alert status

\begin{tabular}{|c|c|c|c|}
\hline \multicolumn{2}{|l|}{ Semi-emergency } & \multirow[t]{2}{*}{ Emergency } & \multirow[t]{2}{*}{ Acute emergency } \\
\hline Category A & Category B & & \\
\hline $\begin{array}{l}\text { Intestinal obstruction } \\
\text { (e.g., anorectal malformation, intesti- } \\
\text { nal atresia, oesophageal atresia) }\end{array}$ & $\begin{array}{l}\text { Critical vascular access-(failed } \\
\text { peripherally inserted central cath- } \\
\text { eter insertion under interventional } \\
\text { radiology) }\end{array}$ & Perforated viscus & Malrotation with volvulus \\
\hline Congenital diaphragmatic hernia & Paediatric oncology cases & $\begin{array}{l}\text { Intussusception (failed pneumatic } \\
\text { reduction) }\end{array}$ & $\begin{array}{l}\text { Severe trauma with } \\
\text { uncontrolled bleeding }\end{array}$ \\
\hline $\begin{array}{l}\text { Failure of non-operative management } \\
\text { of the following: }\end{array}$ & & Obstructed inguinal hernia & \\
\hline $\begin{array}{l}\text { Gastroschisis-failure of non-opera- } \\
\text { tive reduction }\end{array}$ & & $\begin{array}{l}\text { Necrotising enterocolitis with per- } \\
\text { foration }\end{array}$ & \\
\hline $\begin{array}{l}\text { Appendicitis-failure of conservative } \\
\text { management }\end{array}$ & & Gonadal torsion & \\
\hline
\end{tabular}

referrals, identification of the appropriate teams for performing diagnostic/screening COVID-19 swabs for patients in the paediatric surgical wards, emergency department, Neonatal Intensive Care Unit and Paediatric Intensive Care Unit.

Guidelines concerning procedures such as pneumatic intussusception reductions were established in collaboration with colleagues from the Department of Medical Imaging. Protocols concerning sedation, appropriate use of PPE and use of the Interventional Radiology Suite were discussed and agreed upon across both services. This was to ensure that the risk of this aerosol generating procedure was minimised and appropriate physical distancing (where appropriate) was observed.

Due to the risk of COVID-19 transmission via aerosol generating procedures, a moratorium on all minimal invasive surgery (MIS) procedures were proposed. All MIS procedures performed previously were done as open procedures.

\section{Redeployment of manpower}

The challenges faced including clinical work load and shortage of manpower during this pandemic varied from specialty to specialty. We recognised that the general outpatients departments and emergency department faced acute shortages of manpower due to COVID-19 exposure related quarantines and increase of patient load. Members of our team volunteered to fill in shift slots in the adult and paediatric emergency departments. We also had members of our team be part of the COVID-19 swab teams who were on standby to perform pre-surgery screening swabs. These swab teams assisted in primary care out-patient clinics as well. A key member of the division headed the Operating Theatre (OT) COVID-19 team. The OT COVID-19 team was tasked with drawing up guidelines for pre-surgical screening, management of the semi-emergency theatre lists and assisting primary surgeons in surgeries performed for PUIs and COVID-19 positive patients, regardless of specialty.

\section{Education and training}

\section{COVID-19-related education and training programs}

We recognised the need for a structured, well thought out education and training program early in our fight against this pandemic. A member of the paediatric surgical division volunteered to create awareness level courses which were made compulsory for all members of the Department of Surgery. The online-course included resources developed and pooled together from the Infectious Disease Unit and Occupational, Safety, Health and Environment Unit of UMMC. This course content included the mode of transmission, natural history, screening processes and workflow, HCW exposure and psychosocial support. The Division of Paediatric Surgery and Division of General Surgery developed instructional videos for appropriate donning and doffing of PPEs and Powered Air Purifying Respirators (PAPR). These videos were made available via the Official UMMC Online Portal and subsequently used as references for all surgical services throughout the hospital.

\section{Surgical training and education}

Due to the reduced number of emergency and elective surgeries, the concern was that paediatric surgery trainees were not getting adequate surgical exposure. During this period, we devised do-it-yourself (DIY) surgical simulation modules with accompanying clinical vignettes to mimic intraoperative scenarios (vascular and bowel anastomosis). We minimised disruption of weekly learning activities such as Journal Clubs and case discussions during this period by 
switching to online platforms such as Skype, Google Meet, and Zoom.

\section{Psychosocial support initiatives for HCWs and co-ordination of community based efforts}

Our proposal to develop an engagement and e-townhall meeting platform for UMMC HCWs and support staff was well received by the hospital management. A three session per week online engagement session was held by the hospital management, moderated by a member of our team and involved participation of panellists from the Department of Psychological Department, Infectious Disease Unit, Occupational, Safety, Health and Environment Unit, Department of Primary Care Medicine and Social and Preventive Medicine Department. This initiative provided a platform for frontliners and support staff to obtain updates, provide feedback and put forth questions to the management team. We also assisted the management team in coordinating the sourcing and delivery of donations in the form of PPEs from nongovernmental organisations (NGOs) to the hospital.

\section{Results}

\section{Adaptation of clinical services}

The outcomes from the changes in delivery and management of our clinical services are summarised in Table 3.

\section{Education and training}

With the use of electronic media, we were able to target and disseminate critical information and safe practices in the context of COVID-19 in a surgical setting to a large number of HCWs in the department of surgery whilst still observing appropriate social distancing measures. Due to the complexity of organising fix-timed educational/awareness sessions, the training videos and slides made available online were invaluable tools for educating and updating $\mathrm{HCW}$ s with differing work schedules.

Surgical training activities were modified to meet the current restrictions posed by the pandemic. The migration to online video-conferencing platforms enabled us to evaluate the strengths and weaknesses of each individual platform and use the appropriate platform for specific activities. The use of these platforms had also enabled engagement of division members who were not on-site either due to being placed under quarantine or being redeployed to areas of other needs. The DIY skills modules enabled trainers to provide real-time feedback and closely inspect the outcome of the exercise.

\section{Psychosocial support initiatives for HCWs and coordination of community based efforts}

The planning and execution of the hospital management engagement and e-townhall initiative online, by a member of the division birthed an avenue for front liners and members of support staff to exchange experiences and raise concerns related to the COVID-19 pandemic in our local context. This initiative enabled HCWs from various departments to share their perspectives and allowed the management to actively engage individuals and groups in need of support. Interactions were recorded and questions posed during these sessions, were collated, provided written replies, and posted in sites accessible to HCWs in our centre.

\section{Discussion}

The lack of precedents in navigating through a pandemic of this scale, within our lifetime, has made the challenge of formulating and implementing changes to the delivery of surgical services and training that much more daunting [1]. The biggest challenge we faced were to formulate a set of guidelines that ensured the safety of patients and healthcare personnel alike, at a time when there was limited published literature on the delivery of paediatric surgical service during a pandemic.

Over the course of time, the eventual reduction of COVID-19 cases led to a conditional MCO (CMCO) and now the announcement of a recovery MCO (RMCO) phase. This has led to the gradual lifting and easing of the hospital alert status (Table 1) and gradual resumption to normalcy. During this phases, we were able to review the measures via consultation with our peers form the hospital COVID19 taskforce to adjust the measures taken in line with the experiences learnt from contemporaries globally.

We found that our measures of performing and confirming COVID-19 negative swabs on all on all elective preoperative patients prior to surgery and proceeding with surgery using PPE as we did pre COVID-19, resulted in no COVID-19 cases amongst health care workers involved in the surgery and patients alike. For life-threatening emergency procedures and acute emergencies that could not wait for COVID-19 swab turnover times, additional precautions were taken by ensuring all theatre personnel were donning full PPEs. Surgical scrub teams and anaesthetic teams donned powered air respiratory purifiers (PAPR) with full PPE for PUIs as a safety precaution. These measures were largely consistent with surgical guidelines developed by other centres [2-4]. We had no transmission of the SARSCoV-2 to any healthcare personnel or patients in our hospital during this entire period. 


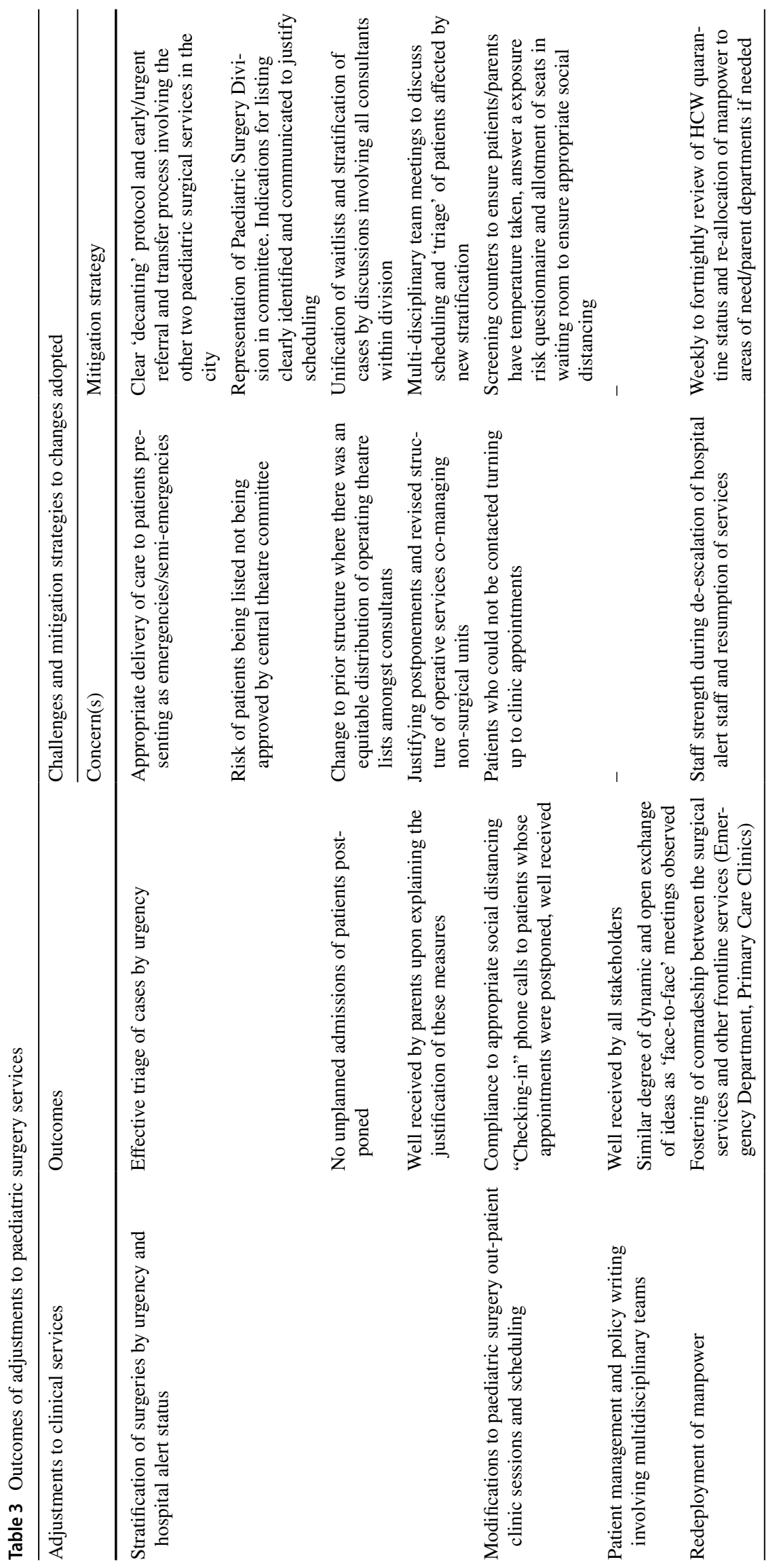


As more publications on measures taken by surgical services began to emerge, we were able to compare our response and learn from the experiences of our peers globally. Our initial response in limiting services by gauging the severity of the pandemic in our local context and resource utilisation by the hospital were consistent with the practices of other surgical services in other epicentres [5-8]. We were able to avert complications resulting from restriction in instituting appropriate surgical care in our centre, as we had mechanisms in place to "decant" patients requiring early care to the other two paediatric surgery services in the city. During this outbreak, we had reduced elective surgeries by approximately $80 \%$, the remaining $20 \%$ of patients which could not be postponed were oncology patients requiring definitive surgery and vascular access. This was consistent with the estimated cancellations observed amongst upper middle income countries [9]. These patients were relisted as semi-emergencies. However, the challenge remains in resuming services and addressing the backlog resulting from the postponement of non-urgent elective procedures and outpatient clinic visits. We are addressing this challenge by shifting our approach from a designated individual consultant based elective surgical list and clinic (pre COVID-19 period), to consolidated clinic sessions and theatre lists to address all outstanding/postponed cases in order of priority. The eventual reintroduction of MIS services with precautions during creation and evacuation of pneumoperitoneum and the use of filtration systems to minimise risk form aerosols were consistent with recommendations by Endoscopic and Laparoscopic Surgeons of Asia (ELSA) [10].

This study has also looked at the other roles played an academic paediatric surgical centre during the pandemic. We had chosen to place some emphasis on areas not widely reported which includes the evolution of surgical training in the face of a limited surgical case load. We developed alternatives to ensure continuity of surgical skills training and surgical education, to address the lack of patient/case exposure.

Our ability to plan and implement these changes within 1-2 weeks of the announcement of the MCO (lockdown) in our country has been largely attributable to all stakeholders irrespective of background, having a unified vision in tackling this challenge. The expansive unified vision includes willingness to cede control when appropriate, striking a balance between meeting departments/divisions needs whilst aligning to organisational needs for the greater good. Despite our swift initial response, we were constantly evaluating our measures, seeking guidance and learning from the experience from our peers in various epicentres of this disease.

We acknowledge the limitations of this study, as there is still limited literature outlining the response of paediatric surgical services specifically, to this pandemic. We are also cognisant of the fact that this is a descriptive study. The measures taken will still require re-evaluation. We acknowledge that the new normal in itself is a dynamic, evolving process.

\section{Conclusion}

The COVID-19 pandemic has demanded members of the surgical fraternity to have a thorough re-look at the way we have been providing specialised surgical care. As surgeons, we need to look beyond tangible indicators of competency and tap into our leadership qualities, communication skills, and emotional resilience. In a rapidly evolving pandemic, the ability to perform a quick assessment of limitations that lie ahead, ability to adapt to changes in the roles we can play and ability to take precise, impactful actions carry a significant weight in the unified fight against this pandemic. The constant evolution of knowledge and practices in the context of surgical services in a pandemic provides us the impetus to strive to improve our approach by drawing on these experiences.

Acknowledgements We acknowledge the following members of the Department of Surgery for their contribution: Prof Dr April Camilla Roslani, Prof Dr Thambidorai, Prof Dr Yik Yee Ian, Dr Ravindran Karuppiah, Dr Ruben Gregory Xavier, Dr Kanesh Kumaran Seevalingam, Dr Muhammad Syafiq Idris

Funding The authors did not receive any for the production of this article/letter.

\section{Compliance with ethical standards}

Conflict of interest All authors have no conflict of interest to declare.

Ethical approval This article does not contain any studies with human participants or animals performed by any of the authors.

\section{Reference}

1. World Health Organization (2019) Coronavirus disease (COVID19) technical guidance: surveillance and case definitions. WHO website: https://www.who.int/emergencies/diseases/novel-coron avirus-26.

2. Karaca AS, Özmen MM, Uçar AD, Yastı AÇ, Demirer S (2020) COVID-19'lu hastalarda genel cerrahi ameliyathane uygulamaları. Turk J Surg 36(1):6-10

3. Wong J, Goh QY, Tan Z, Lie SA, Tay YC, Ng SY, Soh CR (2020) Preparing for a COVID-19 pandemic: a review of operating room outbreak response measures in a large tertiary hospital in Singapore. Can J Anesth/J Can Anesth 67:732-745

4. Royal College of Surgeons (2020) Updated general surgery guidance on COVID-19. https://www.rcseng.ac.uk/coronavirus/joint -guidance-for-surgeons-v2/. Accessed 15 Apr 2020

5. Søreide K, Hallet J, Matthews JB, Schnitzbauer AA, Line PD, Lai P, Otero J, Callegaro D, Warner SG, Baxter NN, Teh C, NgKamstra J, Meara JG, Hagander L, Lorenzon L (2020) Immediate 
and long-term impact of the COVID-19 pandemic on delivery of surgical services. Br J Surg. https://doi.org/10.1002/bjs.11670

6. Chopra V, Toner E, Waldhorn R, Washer L (2020) How should U.S. hospitals prepare for coronavirus disease 2019 (COVID-19)? Ann Intern Med 172(9):621-622

7. Zhu W, Wang Y, Xiao K, Zhang H, Tian Y, Clifford SP, Huang J (2020) Establishing and managing a temporary coronavirus disease 2019 specialty hospital in Wuhan, China. Anesthesiology 132(6):1339-1345

8. Iacobucci G (2020) COVID-19: all non-urgent elective surgery is suspended for at least three months in England. Br Med J 368:m1106

9. Nepogodiev D, Bhangu A (2020) Elective surgery cancellations due to the COVID-19 pandemic: global predictive modelling to inform surgical recovery plans. Br J Surg. https://doi.org/10.1002/ bjs. 11746

10. Shabbir A, Menon RK, Somani J, So JB, Ozman M, Chiu PW, Lomanto D (2020) ELSA recommendations for minimally invasive surgery during a community spread pandemic: a centered approach in Asia from widespread to recovery phases. Surg Endosc. https://doi.org/10.1007/s00464-020-07618-0

Publisher's Note Springer Nature remains neutral with regard to jurisdictional claims in published maps and institutional affiliations. 